\title{
DEGENERATION OF JOINTS IN HAEMOPHILIACS UNDER TREATMENT BY MODERN METHODS
}

\author{
S. van Creveld, Huizen, Ph. J. Hoedemaeker, Groningen, M. J. Kingma, Groningen, and \\ C. A. Wagenvoort, Amsterdam, The Netherlands \\ From the Haemophilia Clinic, Huizen, the Department of Pathology, University of Groningen, \\ and the Department of Pathology, University of Amsterdam
}

The expectation of life of patients suffering from haemophilia A and B has greatly improved during the past decade. The prompt treatment of haemorrhages with plasma products containing the clotting factors that are lacking and the administration of these products during surgical treatment have contributed to the more favourable prognosis. A contribution can also be made nowadays by the prevention of haemorrhages.

The question arises whether the effect of modern treatment of haemorrhages can also be observed in the degenerative changes in the joints, and whether these changes are worse in untreated patients than in patients who were treated immediately for intra-articular haemorrhage. This paper describes the changes observed in the knees and elbows of three young patients treated for a considerable time for haemophilia $\mathrm{A}$, who died in traffic accidents.

\section{CASE REPORTS}

Case 1-A fourteen-year-old boy suffering from haemophilia A had been treated for intraarticular haemorrhages and haematuria on several occasions. He was in hospital twice for correction of talipes equinus. After this he was free of haemorrhages for a considerable time. Table I shows the transfusions and the plasma products that he received during the treatment

TABLE I

Case 1-Transfusions Received for Haemorrhages in Right Elbow and LEFT KNEE JOINT

\begin{tabular}{|c|c|c|c|c|c|}
\hline Joint & $\begin{array}{c}\text { Age at time of } \\
\text { haemorrhage } \\
\text { (years) }\end{array}$ & $\begin{array}{l}\text { Number of } \\
\text { transfusions }\end{array}$ & $\begin{array}{c}\text { Duration of } \\
\text { treatment } \\
\text { (days) }\end{array}$ & \multicolumn{2}{|c|}{$\begin{array}{c}\text { Total } \\
\text { transfused } \\
\text { (millilitres) }\end{array}$} \\
\hline \multirow{2}{*}{ Right elbow } & 10 & 6 & 6 & Plasma & 550 \\
\hline & 11 & 5 & 3 & Plasma & 600 \\
\hline \multirow{5}{*}{ Left knee } & 8 & 5 & 5 & $\begin{array}{l}\text { Plasma } \\
\text { Fibrinogen }\end{array}$ & $\begin{array}{l}400 \\
600\end{array}$ \\
\hline & 8 & 5 & 7 & $\begin{array}{l}\text { Plasma } \\
\text { Fibrinogen }\end{array}$ & $\begin{array}{l}300 \\
450\end{array}$ \\
\hline & 10 & 8 & 5 & Plasma & 1,225 \\
\hline & $10 \frac{1}{2}$ & 5 & 4 & Plasma & 550 \\
\hline & $10 \frac{1}{2}$ & 10 & 11 & $\begin{array}{l}\text { Plasma } \\
\text { Fibrinogen } 1\end{array}$ & $\begin{array}{r}200 \\
1,200\end{array}$ \\
\hline
\end{tabular}

of haemorrhages in the left knee and the right elbow. In general he was treated promptly for haemorrhage. Radiographs of the joints showed a normal left elbow. The right elbow was more advanced in development. The epiphyses of the radius and ulna were larger and the epiphysial plates narrower. The right knee was normal. The left knee showed a narrowed joint space and the condyles of tibia and femur were enlarged. The articular surfaces were 
irregular and the structure of the bone was coarse. The changes were consistent with second degree haemophilic arthritis.

In July 1967 the patient was involved in a car accident. On admission to hospital he was found to have a greenstick fracture of the right tibia and extensive haemorrhages in the back and limbs. Later, signs of intracranial haemorrhage appeared and in spite of treatment the patient died ten hours after the accident.

Necropsy showed a large right subdural haemorrhage. Apart from the bruises on the back and arms and legs, no other haemorrhages were found. The right elbow and the left knee joint, which showed the worst changes during life, were removed for further examination. The synovial membrane of these joints was brown and showed the remains of old haemorrhages (Fig. 1). The articular surfaces were irregular and showed defects.

Histological examination showed similar changes in elbow and knee. There was destruction of the central parts of the surface cartilage with areas of fibrosis, probably due to old haemorrhages. Clefts had formed in the articular surface, partly parallel and partly at right angles to the surface. Sometimes these clefts reached the epiphysial bone. Chondrocytes were lying in clusters (Fig. 2) and showed

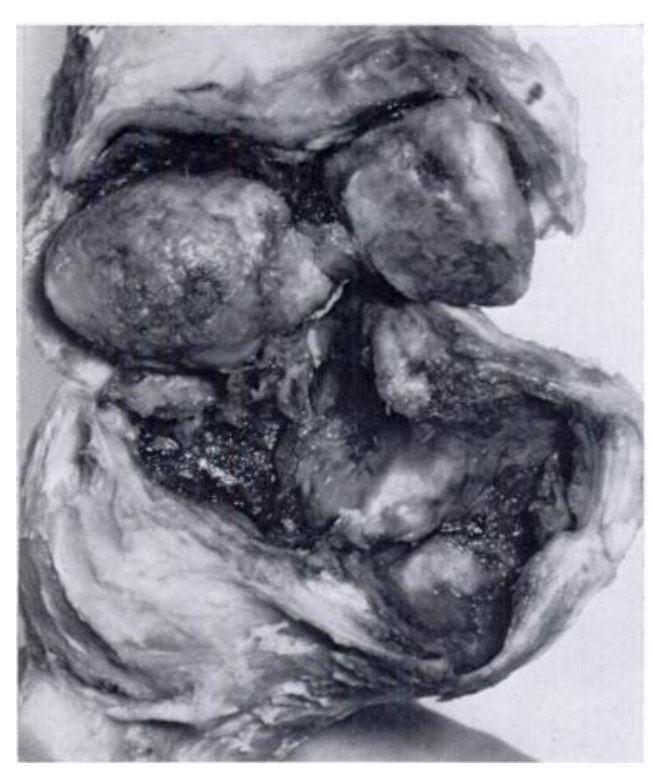

Fig. 1

Case 1-Irregular articular surfaces with defects and with staining of the synovial membrane. hyperchromatic nuclei and cytoplasmic vacuoles. Ossification was irregular (Fig. 3), and extensive areas of fibrosis could sometimes be seen extending into the marrow (Fig. 4).

Case 2-A seventeen-year-old boy had been known for several years to suffer from haemophilia A. He suffered several haemorrhages, especially in the joints, with consequent limitation of

TABLE II

CASE 2-Transfusions Received for HaEmorrhages into Right KNEE JOINT

\begin{tabular}{|c|c|c|c|c|}
\hline $\begin{array}{c}\text { Age at time of } \\
\text { haemorrhage } \\
\text { (years) }\end{array}$ & $\begin{array}{l}\text { Number of } \\
\text { transfusions }\end{array}$ & $\begin{array}{l}\text { Duration of } \\
\text { treatment } \\
\text { (days) }\end{array}$ & $\begin{array}{r}\text { Total } \\
\text { transfus } \\
\text { (millilitr }\end{array}$ & \\
\hline 7 & 7 & 8 & $\begin{array}{l}\text { Blood } \\
\text { Plasma }\end{array}$ & $\begin{array}{r}300 \\
1,400\end{array}$ \\
\hline 11 & 5 & 6 & $\begin{array}{l}\text { Fibrinogen } \\
\text { Plasma }\end{array}$ & $\begin{array}{l}450 \\
200\end{array}$ \\
\hline 13 & 6 & 6 & $\begin{array}{l}\text { Fibrinogen } \\
\text { Plasma }\end{array}$ & $\begin{array}{l}750 \\
200\end{array}$ \\
\hline
\end{tabular}

movement of the joints, and he also had right peroneal palsy. He suffered osteolysis of the calcaneus following a haemorrhage under his right foot (van Creveld and Kingma 1961). He was using a below-knee splint on the right leg. In general, though not always, the treatment in this patient was immediate. Table II shows a survey of the treatment given to the patient for haemorrhages in his right knee joint.

VOL. 53 B, NO. 2, MAY 1971 


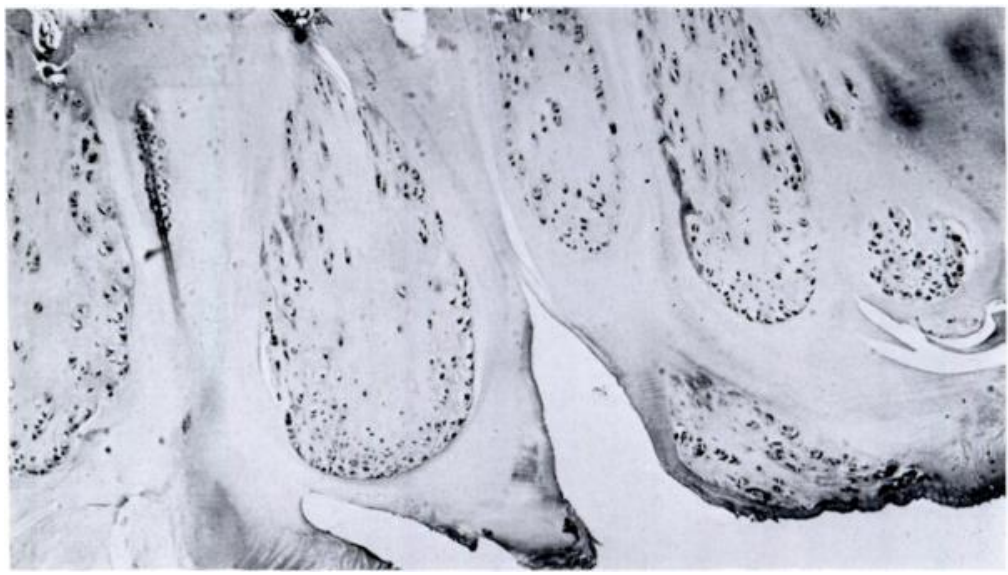

FIG. 2

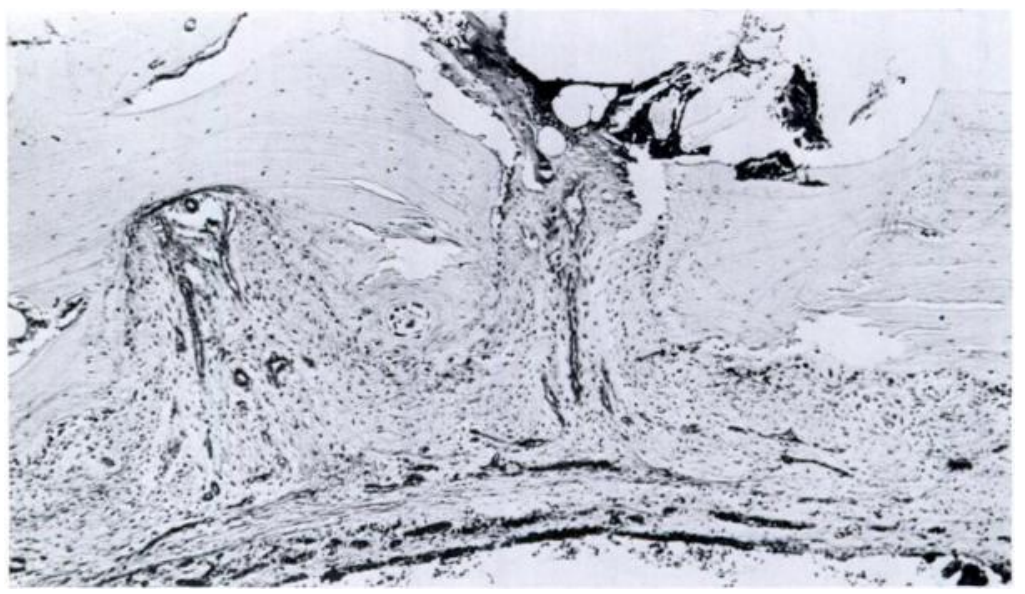

FIG. 3

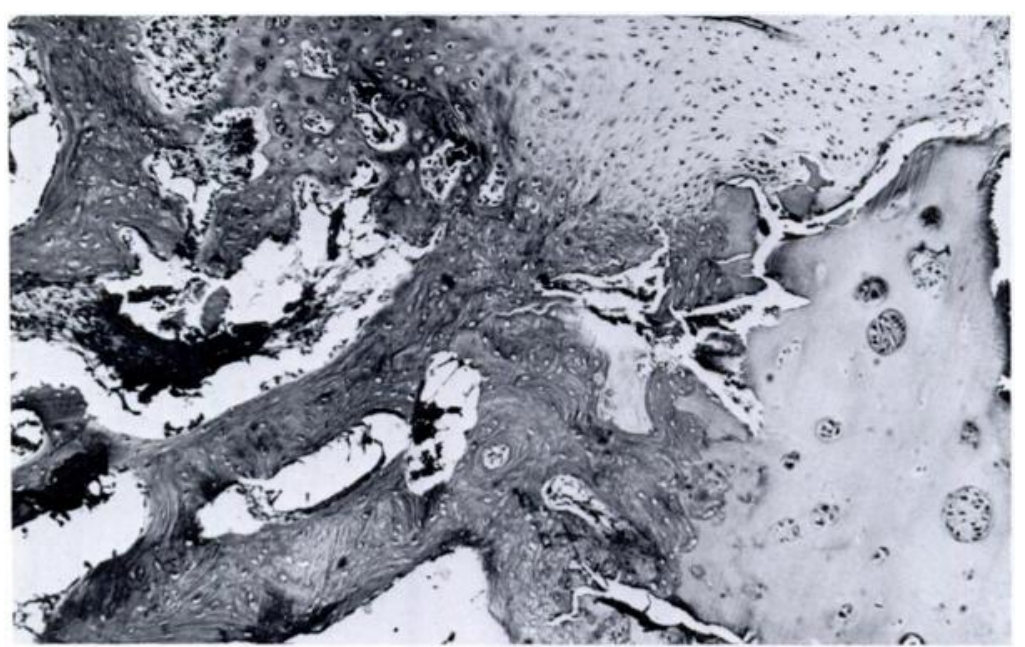

FIG. 4

Case 1-Histological appearances. Figure 2-Clusters of chondrocytes. Figure 3 -Irregular ossification and extensive areas of fibrosis. Figure 4 -Areas of fibrosis extending into the bone marrow. 
Examination showed swollen disfigured knee joints with movement from 15 to 90 degrees in the left and 5 to 85 degrees in the right. Radiographs showed narrow joint spaces and irregular articular surfaces. The bone was rarefied.

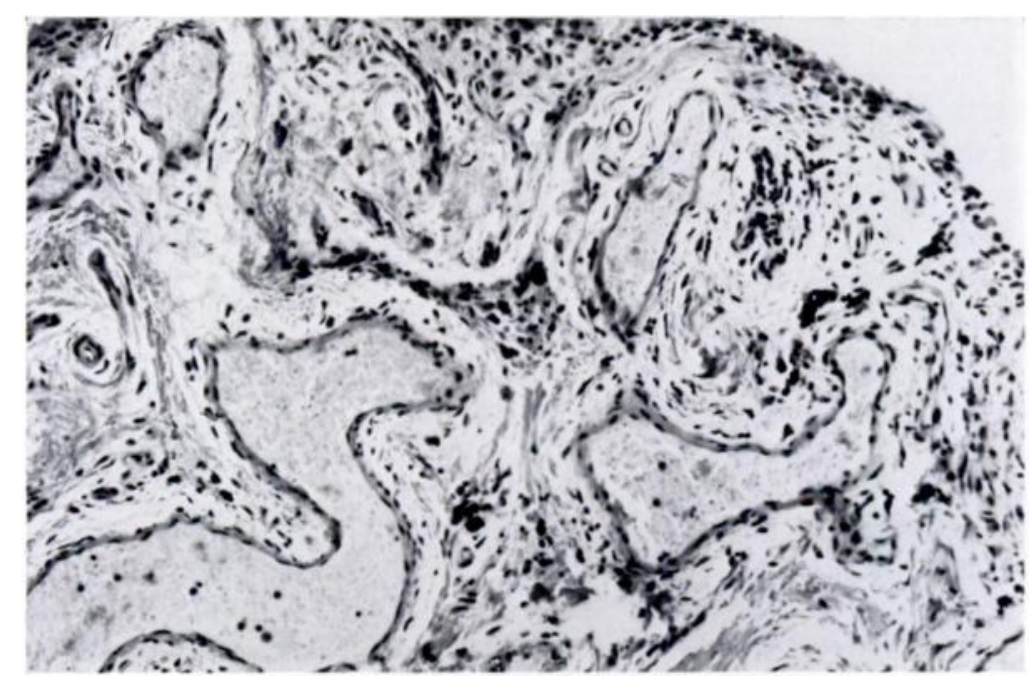

Fig. 5

Case 2-Histological appearance of synovial membrane. Infiltration with mononuclear cells, some containing iron.

In August 1967 the patient was involved in a motor-cycle accident and died of a cerebral haemorrhage shortly after admission to a neurosurgical unit.

The right knee joint was examined. The synovial membrane was brown and the articular surfaces had been destroyed. Histological examination of the synovial membrane showed infiltration with mononuclear cells, some of which contained iron (Fig. 5). There was fibrosis and degeneration of the articular cartilage, and clefts were present. The epiphysial plate seemed to be interrupted.

Case 3-An eight-year-old boy suffering from haemophilia A was admitted to our clinic several times because of haematuria and other acute haemorrhages. Intra-articular haemorrhages were relatively infrequent: there were three haemorrhages in the right knee joint which responded poorly to treatment, and it appeared that he developed anticoagulant antibodies. Because of this he did not receive any more transfusions.

Examination showed bilateral genu valgum but the function of the joints was not impaired. Radiographs of the left knee showed irregular surfaces and decalcification of bone. The right knee was normal.

In 1968 the boy was involved in a car accident and four days later suffered a right hemiplegia. He died sixteen days after the accident. At necropsy the left knee joint was removed for further examination. The synovial membrane was brown, but there were only minor degenerative changes (Fig. 6). Histological examination showed infiltration of the

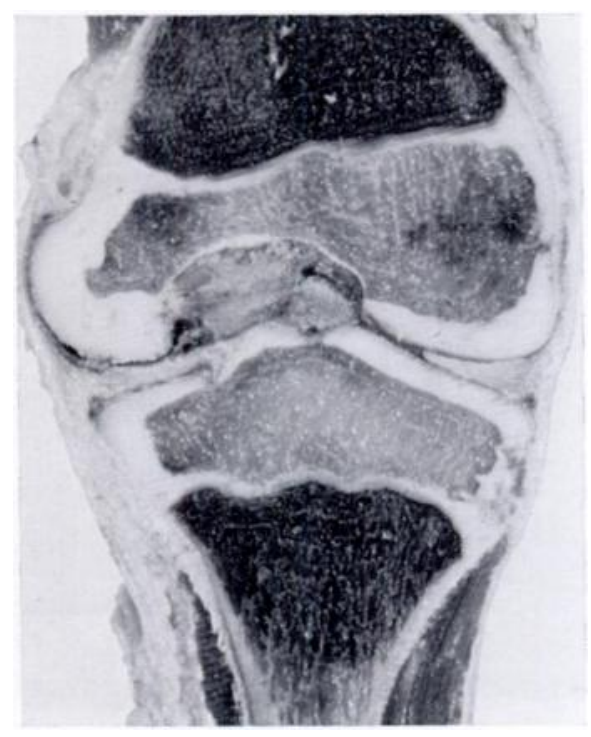

Fig. 6

Case 3-Dissection of the knee joint. Only minor degenerative changes. 
synovial membrane with local accumulation of iron. In a few places the cartilage showed clefts and a few clusters of swollen chondrocytes could be observed.

\section{DISCUSSION}

The classical investigations of König (1892) on three knees of two patients made it clear that recurrent intra-articular haemorrhages in patients suffering from haemophilia might result in progressive destruction of the joints. The changes were seen not only within the joints but also in the capsule, cartilage and underlying bone (Bokelmann 1881). König described three stages of joint affection: 1) haemarthrosis, 2) panarthritis, and 3) degeneration. These severe progressive changes in the joints were confirmed by other investigators (Freund 1925; Key 1932; Collins 1949; DePalma and Cotler 1956; Marion, Favre-Gilly, Picault and Gauthier 1965). They were also seen in dogs suffering from haemophilia (Swanton 1957, Webster et al. 1966). The changes observed by Swanton varied from free blood in the joints to a severe haemarthrosis.

The effect of therapy on the progression of these changes was studied by Swanton, Brinkhouse and Roberts (Webster 1966). They compared the articular changes seen in ten haemophilic dogs treated intensively with plasma transfusions with those in ten dogs not so treated. It was shown that immediate and intensive treatment prevented severe articular changes, namely, changes in bone and cartilage and synovial fibrosis. Haemosiderosis of the synovial membrane was present in both groups. Recently, too, attention was drawn to the severe radiographic changes seen in the joints of haemophilic men and dogs (Ahlberg 1965, Jordan 1958, Trueta 1966, Swanton 1957, 1959).

The most important changes seen in the joints of patients with haemophilia were haemosiderosis of the synovial membrane. This could be a reason for the fibrosis seen in the subsynovial and capsular tissues. Furthermore the synovial membrane showed hypertrophy and the formation of villi. The articular capsule was hyperaemic, a state which could easily cause new haemorrhages. Astrup and Sjølin (1958) thought that intra-articular haemorrhages originated from a decreased thromboplastic activity and normal fibrinolytic activity of the synovial membrane. For this reason Storti, Traldi, Tosatti and Davoli (1969) treated a few patients with intra-articular haemorrhages by removing the synovial membrane. They also injected trasylol, an inhibitor of protease, which on previous occasions had caused an immediate arrest of haemorrhage during operation.

The typical articular changes in untreated patients are as follows. After several haemorrhages the fibrous capsule shrinks and the cartilage changes, and becomes thinner and finally disappears. The bone also changes: it atrophies and the structure becomes coarse. The articular surfaces are changed by abnormal growth of the epiphysial plate and because of the cartilaginous defects. These defects are caused by bone cysts probably formed by the resolution of old haemorrhages. Some of these cysts later open into the joint space. By this process the severe arthritis often seen in early age in haemophilic patients is produced.

The effect of treatment-All our patients suffered from a severe haemophilia A, and two (Cases 1 and 2) had several intra-articular haemorrhages. The third patient had had less frequent haemorrhages. There were severe radiographic changes in the knees of the first two patients, and less severe changes in the case of the third. The degenerative changes in the joints were probably not so severe as they would have been without treatment. The question is whether the histological changes too were less severe.

The changes seen in the joints of the first and second patients were rather like those seen in joints of untreated patients: not only was there haemosiderosis but there were also defects in the articular surfaces.

Histological examination showed no synovial fibrosis, nor formation of villi (Key 1932, Collins 1949), but there was typical local destruction of cartilage, probably caused by 
subchondral haemorrhages. It is not clear whether the absence of fibrosis was a result of the treatment; certainly, in other aspects no differences could be observed. The degeneration in the joints of the third patient was much less severe than that in the joints of the first two.

It appears that though the degree of arthritis was not so bad as that in the classical descriptions, the basis of affection was similar. These results are not in agreement with the clinical finding that prompt treatment of the haemorrhages results in an immediate disappearance of the symptoms. However, even if specific therapy is accompanied by aspiration of the joint it seems unlikely that the blood is removed completely. In a large number of aspirations Kerr (1963) removed 0 to 170 millilitres with an average of 25 millilitres of blood from the joint and the remaining blood caused the changes in the synovial membrane, cartilage and eventually the bone.

Our experience indicates that neither prompt treatment nor aspiration of the joint can prevent haemophilic arthritis. At the most the changes are less severe. Only prophylactic therapy can prevent the changes in the joints. Such therapy, however, is applied only on a small scale and brings the danger of the development of anticoagulant antibodies or serum sickness.

The haemosiderosis of the synovial membrane found after even a small intra-articular haemorrhage may well be important in the origin of the degenerative changes in the joint. Iron deposition causes fibrosis in other organs such as the liver, pancreas and lung. The possibility of removing the iron from the joint should be studied. Furthermore, it is necessary to remove the blood from the joint as quickly as possible in order to minimise the danger of degenerative change. In this connection the possibility of intra-articular injection of fibrinolytics should be studied.

\section{SUMMARY}

1. Four joints of three young haemophiliacs who died in traffic accidents have been examined.

2. All patients had received prompt specific treatment for intra-articular and other haemorrhages.

3. Major macroscopic and histological changes were seen in the joints, but these changes were not quite so severe as those described before the days of specific treatment.

4. The possibilities of preventing articular changes and of minimising the effect of blood in the joints are discussed.

\section{REFERENCES}

Ahlberg, $\AA$. (1965): Haemophilia in Sweden. VII Incidence, Treatment and Prophylaxis of Arthropathy and Other Musculo-skeletal Manifestations of Haemophilia A and B. Acta Orthopaedica Scandinavica, Supplementum 77.

Astrup, T., and Sublin, K. E. (1958): Thromboplastic and Fibrinolytic Activity of Human Synovial Membrane and Fibrous Capsular Tissue. Proceedings of the Society for Experimental Biology and Medicine, 97, 852.

BokelmanN, W. (1881): Ueber die Natur und Bedeutung der haemophilen Gelenkaffectionen. Göttingen: Kästner.

Collins, D. H. (1949): The Pathology of Articular and Spinal Diseases, p. 225. London: Edward Arnold \& Co. Creveld, S. van (1969): Prophylaxis of Joint Hemorrhages in Hemophilia. Acta Haematologica, 41, 206.

Creveld, S. van, and Kingma, M. J. (1961): Subperiosteal Haemorrhage in Haemophilia A and B. Acta Paediatrica, 50, 291.

DePalma, A. F. and Cotler, J. M. (1956): Hemophilic Arthropathy. Archives of Surgery, 72, 247.

DePalma, A. F. and Cotler, J. (1956); Hemophilic Arthropathy. Clinical Orthopaedics, 8, 163.

Freund, E. (1925): Die Gelenkerkrankungen der Bluter. Virchow's Archiv für pathologische Anatomie und Physiologie, 256, 158.

Jordan, H. H. (1958): Hemophilic Arthropathies. Springfield, Illinois: Charles C. Thomas.

Kerr, C. B. (1963): The Management of Haemophilia, p. 63. Glebe: Australasian Publishing Co. Ltd.

KeY, J. A. (1932): Hemophilic Arthritis (Bleeder's Joints). Annals of Surgery, 95, 198.

Kingma, M. J., and Creveld, S. van (1967): Haemophilia as a Crippling Disease. Archivum Chirurgicum Neerlandicum, 19, 113.

KöNIG, F. (1892): Die Gelenkerkrankungen bei Blutern mit besonderer Berükcsichtigung der Diagnose. Klin. Vorträge N.F.Nr. XXXVI. Chirurgie, 11, 233.

VOL. 53 B, NO. 2, MAY 1971 
Marion, J., Favre-Gilly, J., Picault, Ch., and Gauthier, J. (1965): Découverte d'une hémophilie à l'occasion d'une intervention pour synovite villeuse du coude. Hémostase, 5, 69.

REINECKE and WoHLwill (1929): Über hämophile Gelenkerkrankung. Archiv für klinische Chirurgie, $154,425$.

Storti, E., Traldi, A., Tosatti, E., and Davoli, P. G. (1969): Synovectomy, a New Approach to Haemophilic Arthropathy. Acta Haematologica, 41, 193.

Swanton, M. C. (1957): The Pathology of Hemarthrosis in Hemophilia. In Hemophilia and Hemophilioid Diseases, p. 219. Edited by K. M. Brinkhous. Chapel Hill: University of North Carolina Press.

Swanton, M. C. (1959): Hemophilic Arthropathy in Dogs. Laboratory Investigation, 8, 1269.

Thомas, H. B. (1936): Some Orthopaedic Findings in Ninety-eight Cases of Hemophilia. Journal of Bone and Joint Surgery, 18, 140.

Trueta, J. (1966): The Orthopaedic Management of Patients with Haemophilia and Christmas Disease. In Treatment of Haemophilia and other Coagulation Disorders, p. 279. Edited by R. Biggs and R. G. Macfarlane. Oxford: Blackwell Scientific Publications.

Webster, W. P., et al. (1966): Haemophilic Arthropathy. P. 18. Proceedings of the Symposium on Haemonhilia, held in conjunction with the XIth Congress of the International Society of Haematology and the International Society of Blood Transfusion, in Sydney, 27th August 1966. Sydney: Haemophilia Society of New South Wales. 